\title{
Chemical and Physical Approaches for the Treatment of Alzheimer's Disease
}

\author{
Jing Li, Wei Zhou, Xiaoli Wu and Kin Tam* \\ Faculty of Health Sciences, University of Macau, Macau, China \\ *Corresponding Author: E-mail: kintam@umac.mo; Tel.: +853-8822-4988; Fax: +853-8822-2314
}

Received: June 18, 2015; Revised: August 20, 2015; Published: September 05, 2015

\begin{abstract}
Alzheimer's disease $(A D)$ is a destructive neurodegenerative disorder, which threatens elderly people in their mental health irreversibly, causing cognitive deficit such as learning difficulties and memory loss. Neurobiological pathogenesis leading to the neuronal dysfunction in $A D$ are mainly rationalized by two hypotheses: 1) extracellular aggregation of the B-amyloid (AB) peptide, which impacts on the normal neuronal pathways through excessive oxidative stress and damages neurons; and 2) intracellular hyperphosphorylation of tau protein, which forms the paired helical filaments, then gravely impacts axonal transport. In this review, we firstly introduce the neurobiological concept of $A D$, and its pathogenesis. Then we review the chemical approaches pointedly directing at $A B$ peptide and tau protein, and the clinical reality of these pharmacological strategies. Thirdly, we discuss a physical approach, deep brain stimulation (DBS), which is receiving considerable attention in recent years due to its success in treating Parkinson disease clinically. DBS delivers current pulses, which are generated by a implanted pacemaker, through electrodes into dysfunctional brain structures to influence neural activities with the possibility to improve the cognitive function. We will summarize the clinical applications of DBS to restore cognitive impairments due to $A D$, and animal studies related with DBS. Finally, we will discuss the current study obstacles and future research development of $D B S$ in preclinical and clinical investigations of $A D$.
\end{abstract}

\section{Keywords}

Alzheimer's disease; neurobiological pathogenesis; $\beta$-amyloid peptide; tau protein; pharmacological strategies; deep brain stimulation

\section{Introduction}

A growing number of people suffer from $A D$ due to the aggravation of social aging and the dilation of average life expectancy, which brings about heavy burden to the families, the society and the whole world [1]. Therefore numerous researchers and clinicians have spent considerable effort to find a cure. The initial histopathologic hallmarks of $A D$ are the presence of intracellular neurofibrillary tangles (NFTs) and extracellular depositional $\beta$-amyloid $(A \beta)$ plaques [2]. Other histopathologic distinctions differing from healthy people are loss of hippocampal neurons and degeneration of synapses [3].

$A D$ is difficult to diagnosis for its inconspicuous initial symptoms. The disruption of episodic memory, emerging firstly in AD patients [4,5], as well as other subsequent cognitive impairments, especially in attention and execution, semantic memory, language expression, and orientation [6,7] may not draw 
attention of patients and their family members. The clinical diagnosis of $A D$ would not be definitive until the cognitive impairments become serious enough to affect normal social function.

Pathogenesis of $A D$ is considered to be the result of the accumulation of the $A \beta$, which is triggered by the overproduction of $A \beta$ and the lack of clearance mechanisms. $A \beta$ self-aggregates into oligomers, and then forms neuritic plaques in brain [8]. The potent synaptotoxin of insoluble $A \beta$ plaques is endangering proteasome function, mitochondrial activity, neuronal function and so forth. On the other hand, hyperphosphorylated tau destabilizes microtubules, resulting in the damage of axonal transport and then leading to neuronal dysfunction [9]. Moreover, hyperphosphorylated tau can self-accumulate into NFTs which are also harmful to neurons. Furthermore, the cleanup process of hyperphosphorylated tau is suppressed by the actions of $A \beta$ [10]. Therefore, $A \beta$ cascade and hyperphosphorylated tau protein represent two essential therapeutic targets for researchers and clinicians.

The effective pharmacological treatment and prevention of $A D$ is exactly the disease-modifying therapies which researchers and clinicians are now trying to develop. As $A \beta$ cascade and hyperphosphorylated tau protein are generally recognized as vital therapeutic targets, the processes of developing disease-modifying therapies are concentrated on them $[11,12]$. Here we address the 4 main strategies focusing on $A \beta$ cascade from different directions, and 5 diverse means aiming at hyperphosphorylated tau in details.

It is important to note that we have already faced many failures in the course of developing diseasemodifying therapies, while it is nice to see some successes in the development of symptomatic treatment therapies [13]. Available drugs nowadays for treating Alzheimer's disease are directing on cholinesterase and $\mathrm{N}$-methyl-D-aspartate (AMDA) receptor, which are donepezil, galantamine, rivastigmine and huperzine $A$, as well as memantine $[1,12,13]$.

In addition to the traditional AD-oriented chemical methods, one physical method, which is called deep brain stimulation (DBS), appears to be a promising approach to modulate the symptoms of some neurodegenerative diseases [14]. Existing for years, DBS is a fairly minimally invasive neurological procedure which involves the implantation of a brain pacemaker sending mild electrical impulses to target encephalic regions, with the aim to treat certain affective and movement disorders [15].

The origins of DBS are connected to the beneficial effects of electrical stimulation in certain deep brain areas, and performed during the stereotactic functional neurosurgery to identify the right position of the electrodes for treating movement disorders and tremor in Parkinson disease (PD) [16]. As the significantly advantageous outcomes and favourable actions result from treatment of PD which is conducted by DBS, it could be beneficial to apply DBS in the context of $A D$, especially to mitigate the symptoms resulting from cognitive impairment.

The objective of this review seeks to unfold a retrospection of the chemical anti-AD researches and clinical reality of chemical treatment, as well as the physical anti-AD strategy in both preclinical and clinical studies.

\section{Chemical Methods to Treat AD}

\subsection{Pharmacological Strategies of Disease-modifying Therapeutic Methods}

\section{$\underline{\text { 2.1.1 A } \beta \text {-targeting Strategies }}$}

$A \beta$ is produced by sequential proteolysis, where the overexpressed amyloid precursor protein (APP) is successively cleaved by $\beta$-secretase in extracellular region, and $\gamma$-secretase in transmembrane domain [17]. 
Alternatively, A $\beta$ would not be generated if APP is cleaved by the $\alpha$-secretase, and another soluble neurotrophic, SAPP $\alpha$ is the hydrolysis product in this case [17]. Details are shown in Figure 1. However, due to the high expression level of $\beta$-secretase, amyloidogenic pathway is more likely to occur than nonamyloidogenic pathway in neurons [18]. $A \beta$ isoforms are proteins containing 36-43 amino acid residues, where $A \beta 40$ and $A \beta 42$ are the two major isoforms. $A \beta 42$ is predominant in the brain parenchyma of $A D$ patients, which may result from fibrillogenic feature. If $A \beta$ cascade is chosen as therapeutic target, four main options seem to be feasible to tackle the problem: (1) suppression of $A \beta$ production, (2) stimulation of $A \beta$ clearance, (3) prevention of $A \beta$ aggregation into amyloid plaques, and (4) raising brain resistance to $A \beta$ $[1,13]$.

(b)

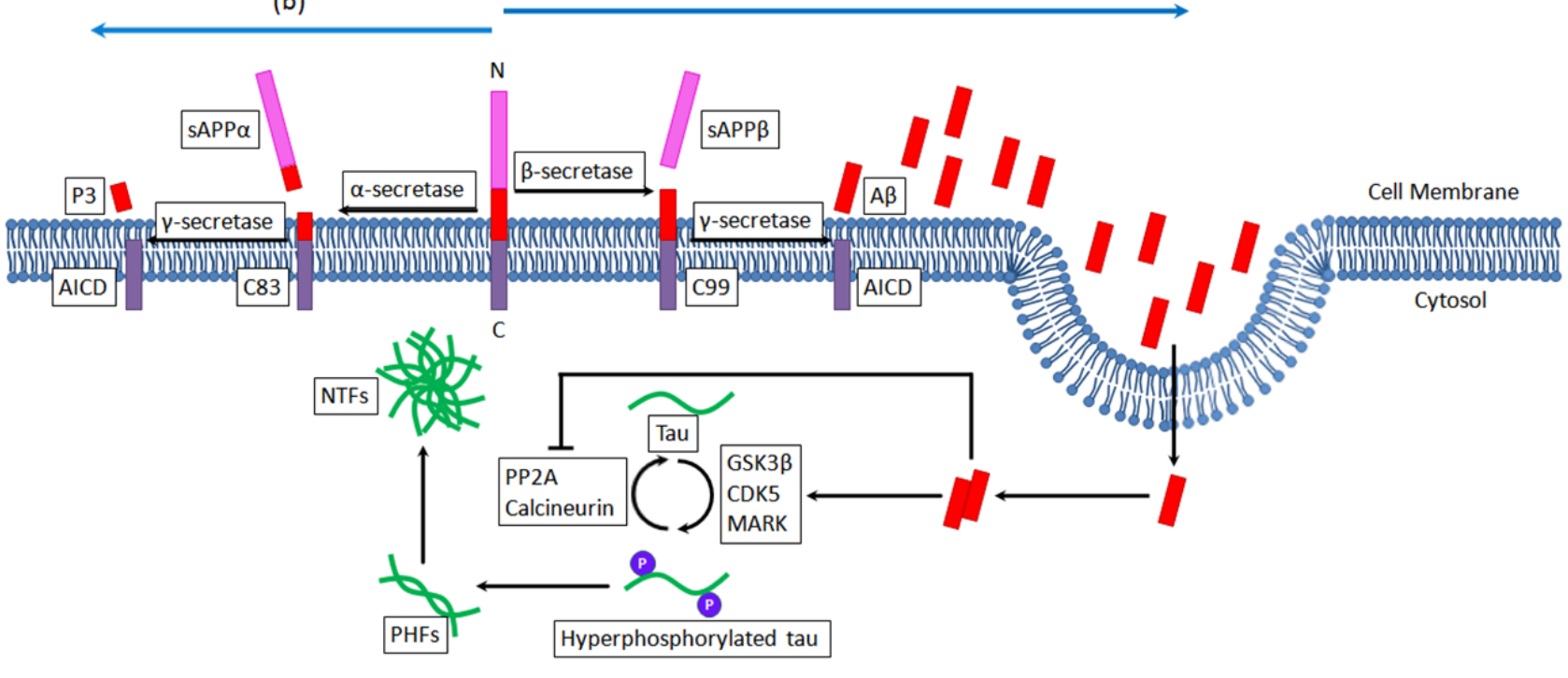

(c)

(d)

Figure 1. $A \beta$ cascade and tau process: (a) Amyloidogenic pathway of APP proteolysis, (b) Non-amyloidogenic pathway of APP processing, (c) Interaction between A $\beta$ cascade and tau process, (d) Tau process.

\subsubsection{Three Strategies of Decreasing AB Production}

The extracellular accumulation of senile plaques composes of the $A \beta$ peptide, which represents one of the two defining lesions in $A D$ brain. $A s$ a vital step of $A D$ pathogenesis, $A \beta$ production is a potentially crucial target for disease-modifying therapeutic methods which attempt to restrain the disease at early stages $[12,19]$.

\subsection{6-secretase inhibition}

$\beta$-secretase is an obvious therapeutic target because it initiates the amyloidogenic processing. However, the development of $\beta$-secretase inhibitors does not appear to be straight forward since the physiological roles and functions of this enzyme are not fully understood [20]. Besides, it could be challenging to develop a blood brain barrier permeable drug which can bind effectively to the large catalytic pocket of the enzyme.

The oral drugs for type 2 diabetes, rosiglitazone and pioglitazone show the ability to inhibit $\beta$-secretase by activating the peroxisome-proliferator activated receptor- $\gamma$ (PPAR $\gamma$ ), which can suppress the expression of APP and $\beta$-secretase [21]. Rosiglitazone has been studied in a large Phase 3 trial with AD patients, but the 
result was negative [22]. And it is also warned by FDA that rosiglitazone may be associated with cardiac risks. Pioglitazone exhibited its therapeutic effect of cognitive and functional improvements, and the effect of disease stabilization in diabetic patients with $A D$ in a Japanese open-label study [23]. And one Phase 2 study showed no unanticipated or serious adverse events attributable to pioglitazone over a long-term exposure in nondiabetic patients with $A D$, though no significant treatment effect was observed [24]. An ongoing Phase 3 trial (5,800 cognitively normal participants in the United States, Australia, Europe, and Russia) is underway to evaluate pioglitazone's ability to delay this diagnosis in people deemed high-risk with AD [25].

Another $\beta$-secretase inhibitor, CTS-21166 has been evaluated in a Phase 1 study. Preliminary clinical results suggested that this inhibitor was able to reduce the $A \beta$ levels in human plasma [26]. Other $\beta$ secretase inhibitors such as GSK188909 and PMS777 have been reported to reduce the level of A 342 in vitro $[27,28]$, but no clinical trial is conducted now.

With more promising $\beta$-secretase inhibitors come to the horizon, it is expected that some of them might be developed into candidate drugs showing positive indications in future clinical evaluations for the modulation of cognitive decline in AD patients [29].

\subsubsection{2 $\gamma$-secretase modulation/inhibition}

Similar to $\beta$-secretase, $\gamma$-secretase also has many other substrates besides APP, including the Notch receptor and other neuronal substrates. Notch, involving in cell differentiation, is necessary for growth and development. The side effects of $\gamma$-secretase inhibition which is associated with Notch (gastrointestinal and haematological toxicity, skin cancer, and changes in hair colour) have been hindering the development of $\gamma^{-}$ secretase inhibitors [30].

Several $Y$-secretase inhibitors linked with AD, like semagacestat (LY-450139), PF-3084014, avagacestat (BMS-708163), begacestat (GSI-953), and NIC5-15 have reached clinical trial. Semagacestat is the first $\gamma^{-}$ secretase inhibitor to have been taken into Phase 3 clinical trials. However, the trials were suspended because of no efficacy on cognition or function and increased risk of infections and skin cancer [31]. A Phase 1 clinical trial with healthy subjects showed that PF-3084014 with high selectivity for APP had good activity exhibiting a dose-dependent decrease in plasma $A \beta$ concentrations, though its effects on cerebrospinal fluid (CSF) were low [32].

Avagacestat, begacestat and NIC5-15 are Notch-sparing $\mathrm{Y}$-secretase inhibitors, which can be considered to have the effect of decreasing CSF A $\beta$ concentration without arousing Notch-related toxicity. However, most patients ceased the Phase 2 trials with avagacestat because of gastrointestinal and dermatological side effects such as diarrhea, nausea, vomiting, rash, and itching skin, and even nonmelanoma skin cancers [33]. Begacestat has been tested in a Phase 1 trial with the consequence of reducing $A \beta$ concentrations in the plasma (with delayed rebound) [34], without significant reduction of CSF AB40. NIC5-15 is a small and single monosaccharide exited in soy and other plants and fruits. It has been tested in AD patients in a finished Phase 2 trial to assess its safety and efficacy, and the preliminary results have shown that this compound is safe and well tolerated [35].The other Phase 2 trial was initiated in 2012, and no study results have been reported [36].

With selective inhibition of APP proteolysis and no Notch-based adverse effects, $\gamma$-secretase modulators have been given much attention, which can shift the $\gamma$-secretase cleavage point to obtain nontoxic, shorter $A \beta$ isoforms. Several non-steroidal anti-inflammatory drugs (NSAIDs) were reported as A 342 -lowering $\gamma$ secretase modulators, including sulindacsulfide, indomethacin, and ibuprofen. They can bind to APP to 
reduce the generation of $A \beta 40$ and $A \beta 42$, and enhance the production of $A \beta 38$ [37]. As a promising candidate, tarenflurbil, the $R$ enantiomer of fluriprofen, failed in Phase 3 trial for $A D$ patients. Disappointingly, AD patients treated with this compound showed progressive deterioration in cognitive functions and daily activities. This negative result might be ascribed to the low $\gamma$-secretase modulator potency and poor CNS penetration [38]. And another compound called CHF-5074 showed antiinflammatory benefit and improvement of executive function in Phase 2 trial, with adverse events of mild diarrhoea, dizziness and backache [39]. Not unexpectedly, another Phase 2 trial with CHF-5074 was withdrawn from clinicaltrials.gov prior to enrolment [40].

\subsubsection{3 $\alpha$-secretase activation}

Since $\alpha$-secretase competes for cleaving APP with $\beta$-secretase, enhancement of $\alpha$-secretase activity can upregulate non-amyloidogenic pathway, which may decrease $A \beta$ generation and have therapeutic potential. A Phase 2a trial with etazolate (EHT-0202) has elaborated that this drug is safe for AD patients and well tolerated, which offer a good support for further studies of this compound [41]. Bryostatin-1 is another compound which has entered Phase 2 trials to evaluate its safety, tolerability and potential effectiveness, for it showed encouraging capacities of inhibiting $A \beta 40$ and $A \beta 42$, and improving behavioural assessment in AD mouse model [42]. However, the process of this compound in one Phase 2 trial is uncovered [43], and one was terminated [44], and another is not open yet for participant recruitment [45]. It remains to be seen if this compound shows positive indications. Another compound, Exebryl-1, also showed positive results with substantial reduction of $A \beta$ formation and aggregation in $A D$ transgenic mice, it has been regarded as another promising candidate to cure AD [46]. Accordingly, clinical evaluation is expected to take place in China and US.

\subsubsection{Promotion of AB Clearance}

\subsection{Immunotherapy}

Active (vaccination) and passive (monoclonal antibodies) immunizations have been focused on to remove soluble and aggregated $A \beta$ for their promising data from in vitro researches and animal studies.

One of the premier active immunization trials was conducted using human $A \beta 42$ (AN-1792) and a Thelper adjuvant (QS-21) in combination. However, the Phase 2 study was terminated because of severe side effect, meningoencephalitis, and low probability of predetermined antibody response [47].

The development of new vaccines without the amino acid parts that stimulating $T$ cells has been considered to avoid neuroinflammation and toxicity. As CAD-106 has shown a good safety profile and acceptable antibody response in a Phase 1 trial [48], it is now being tested in Phase 2 trials. ACC-001 and V950 are conjugate of multiple short $A \beta$ fragments, which can cause an immune response based on the $B$ cell epitope that is included in the N-terminal $A \beta$ fragment [13]. V950 was tested in a Phase 1 trial as an aluminium-containing adjuvant [49], which was completed in 2012. ACC-001 was being tested in multiple Phase 2 trials, with or without QS-21. However, ACC-001 has been discontinued from development since May 9, 2013 [50]. A Phase 1/2 trial of ACl-24 began in the year of 2009, to explore the safety, efficacy, and immunogenicity of this liposome vaccine, which showed positive consequence in $A D$ transgenic mice [51]. Another compound UB311 was undergone a Phase 1 study in Taiwan to address the safety, tolerability and immunogenicity issues with favourable results obtained, including positive antibody responses and elevated neuropsychological outcomes without any serious side effects [52]. The other Phase 1 trial held by the same group to monitor long-term efficacy and immunogenicity of the same vaccine was completed in the year of 2011 but no result has reported [53]. A Phase 2 trial of UB311 was reported being initiated by 
United Biochemical, Inc. recently [54].

Some severe side effects induced by vaccination and passive immunotherapy have been considered an alternative immunotherapeutic strategy, which are based on monoclonal antibodies or polyclonal immunoglobulins to promote the clearance of $A \beta$. However, revascularization would be a potential issue for long term treatment of passive immunization, for these therapies could lead to cerebral microhemorrhages related to vascular amyloid deposits [55]. Nevertheless, some monoclonal antibodies have already been tested in AD patients, like solanezumab (LY-2062430), bapineuzumab (AAB-001), and gantenerumab (RG1450), ponezumab (PF-04360365), GSK-933776, MABT-5102A and immunoglobulins (IVIg) [13].

Serious adverse effect, vasogenicedema, occurred in the Phase 2 trial of bapineuzumab, with no significant improvements of cognition and daily activities [56]. Non-significant efficacy and cognitive enhancement were found in APOE $\varepsilon 4$ non-carriers, so two Phase 3 trials of this humanized monoclonal antibody were initiated using APOE $\varepsilon 4$ carriers and non-carriers respectively in mild-to-moderate $A D$ patients. Unfortunately, the consequences were disillusionary and bapineuzumab did not improve clinical outcomes in AD patients [57].

The results of Phase 1 and 2 trials showed that solanezumab might have pharmacological function in AD $[58,59]$, and two Phase 3 trials were held to further explore the efficacy of this humanized monoclonal antibody. However, the disappointing results showed that it failed to provide improvement of cognition and functional ability [60].

As a fully human anti-A $\beta$ antibody, gantenerumab could reduce small plaques by recruiting microglia, and prevents new plaque formation [61]. A Phase 3 trial of gantenerumab in 1,000 mild AD patients was initiated in the year of 2014 [62].

Ponezumab is a humanized IgG2 $\delta$ A monoclonal antibody which can bind to $A \beta 40$. Phase 1 trial manifested its good tolerability in patients with mild-to-moderate $A D$ [63], but two Phase 2 trials showed no effect on the primary endpoints of change in brain or cerebrospinal fluid (CSF) A $\beta$ burden [64].

The safety and tolerability, as well as pharmacokinetics and pharmacodynamics of GSK-933776 were investigated by two Phase 1 trials with positive results $[65,66]$. Further clinical study is expected to take place in due course.

Natural anti-amyloid antibodies have been identified in human intravenous IVIg, which were isolated from pooled plasma of healthy blood donors. A phase 1 trial has been carried out with eight patients treated with IVIg, and been completed with seven patients. The exciting results showed that IVIg prevented the decline of cognitive function in all seven patients and even improved cognition in six [67]. A phase 3 clinical study with more than 360 AD patients was started in 2009. The results from this clinical trial may provide conclusive evidence as to whether IVIg can be used as a treatment option for AD [67].

\subsection{A6-degrading enzymes}

Recent studies have showed that the decreased clearance of $A \beta$ peptide played a more important role than its increased production in sporadic $A D[68,69]$, and the way to upgrade or activate $A \beta$-degrading enzymes would be another potential approach to conquer AD. Several proteinases, such as, neprilysin (NEP) [70, 71], angiotensin-converting enzyme (ACE) [1], plasmin [1], insulin degrading enzyme (IDE) [1], and endothelin converting enzyme (ECE) 1 and 2 [1], were shown to be able to degrade $A \beta$ peptides in vitro or in animal models.

\subsubsection{Suppression of AB Aggregation}


The $A \beta$-induced neurotoxicity has been shown on a number of occasions. Potentially it may be possible to elicit a therapeutic effect by inhibiting the $A \beta$ peptide aggregation. As the only aggregation inhibitor entering Phase 3 trial, tramiprosate (3APS) showed negative clinical efficacy, which resulted in the discontinuation of clinical trial of this drug [72]. Though showing positive results in Phase 2 trials, the development of clioquinol (PBT1) was suspended by its manufacturer [73]. Another compound with the same production line, PBT2, failed to achieve its targets in Phase 2 trials, and failed to show any benefits $[74,75]$. Primary clinical efficacy outcomes of a Phase 2 trial of another compound, ELND005 (scylloinositol), were not significant [76].

\subsubsection{Raising Brain Resistance to AB}

For increasing brain resistance to $A \beta$, one target is the group IV phospholipase A2 (GIVA-PLA2), which is involved in neurovirulence of $A \beta$. Studies showed genetic reduction or ablation of GIVA-PLA2 inhibits $A \beta$ induced cognitive deficit in animal models [77]. However specific drugs to inhibit GIVA-PLA2 remain to be confirmed. The other target is tau protein level since it may involve the mediation of $A \beta$-dependent neuronal dysfunction. It has been showed that genetic reduction or ablation of tau suppresses $A \beta$-induced cognitive deficit, but does not affect the plaque burden or $A \beta$ oligomer levels in animal models [78].

\subsubsection{Tau-targeting Strategies}

Tau protein is a cytoplasmatic microtubule-associated protein that is more frequently found in neurons than non-neuronal cells [79]. The main function of tau is stabilizing axonal microtubules through interacting with tubulin during its polymerization [80]. Abnormally hyperphosphorylated tau develops the paired helical filaments (PHF), which has severe toxicity impairing axonal transport gravely. Tau hypothesis is the main competitor of the $A \beta$ hypothesis in $A D$ pathologies [81], but it is also interacts with $A \beta$ cascade. The strategies concentrated on tau protein mainly based on its phosphorylation, aggregation and misfolding.

\subsubsection{Prevention of Tau Phosphorylation}

The phosphorylation of tau protein, which mainly mediated by microtubule-associated regulatory kinase (MARK), cyclin-dependent kinase-5 (CDK5), and glycogen synthase kinase $3 \beta$ (GSK-3 $\beta$ ), increases dramatically in $A D$ patients $[82,83]$, showing that the inhibitors of tau kinases could have the ability of anti$A D$. Valproate (VPA) showed its inhibitory effects on tau hyperphosphorylation in both AD transgenic mice and SH-SY5Y cell model, which might be realized through both regulating GSK3 $\beta$ and CDK5 signalling pathways [84]. As the first drug aiming at tau hyperphosphorylation has entered Phase 3 trial, valproate showed disappointingly negative results for no improvements on cognitive and functional performance of AD patients [85, 86]. The most studied compound having capacity of suppressing GSK3 $\beta$ is lithium [87], but it did not show its ability of improving working memory in aged 3XTg-AD mice [88], so the most efficacious treatment might be the combination of lithium and other anti-A $\beta$ interventions. Unfortunately, the clinical consequence of a Phase 2 trial showed us the negative side of this drug, which manifested no effect on GSK-3 activity and no improvement in global cognitive performance [89]. Besides inhibiting the action of MAPK, protein phosphatase PP-2A could also increase tau dephosphorylation. The inhibitors of CDK5 seem to impair the development of pathology in tau transgenic mice [90]. The M1 muscarinic agonist AF267B (NGX267) can inhibit GSK-3 $\beta$ [1]. Also, minocycline could inhibit tau aggregation, which associated with the suppression of $A \beta$-induced neuronal death and cognitive impairment in animal models [91].

\subsubsection{Prevention of Tau Aggregation}

Though it is an ordinarily soluble protein, tau forms insoluble, filamentous accumulation in the course of NFTs formation. Inhibitors of tau aggregation independent of phosphorylation have been found and tested 
in cell cultures [92], including $\mathrm{N}$-phenylamines, phenothiazines, thiazolyl-hydrazides, anthraquinones, thiacarbocyanine dyes, polyphenols, aminothienopyridazines, rhodanines, quinoxalines and so on [93].

\subsubsection{Prevention of Tau Misfolding}

Besides tau aggregation, the misfolding of hyperphosphorylated tau is conducive to the pathology of AD. It has been suggested that the misfolding of tau and the development of NFTs might be prevented by molecular chaperones [94]. Moreover, heat shock proteins could activate chaperones to contribute to prevent misfolding of tau [95].

\subsubsection{Anti-phospho Tau Antibodies}

It would be possible to prevent the aggregation of hyperphosphorylated tau in order to limit its neurotoxic effect. Sigurdsson and his colleagues suggested that anti-phospho tau antibodies could inhibit brain aggregated tau and suppress progression of tangle-related behavioural phenotype in mouse models [96].

\subsubsection{Compensation for Tau Function}

Since hyperphosphorylated tau lose the physiological cellular function of binding and stabilizing microtubules, possessing the function of stabilizing microtubules, BMS-241027 may compensate for the loss of normal tau, and then suppress neurodegeneration and succeeding cognitive decline [97]. BMS241027 showed its functions of reversing behavioral and cognitive deficiencies and restraining neuron loss in mouse models $[98,99]$. A Phase 1 trial to evaluate the tolerability and pharmacology of BMS-241027 was completed in 2013, but no consequences have been demonstrated [100].

\subsection{Symptomatic Therapies: Approved Drugs for Treatment in Alzheimer's Disease}

Until now, though there are no available drugs which can cure $A D$, some drugs have the ability to improve symptoms, or slow down their progression in some patients. Current drugs for treating $A D$ have been categorized into two types: one is inhibitors of the acetylcholinesterase (AChEls), and the other one is $\mathrm{N}$-methyl-D-aspartate (NMDA) receptor antagonists, which target glutamatergic and cholinergic neurotransmission to improve the symptoms [13], though their neuroprotective activity nowadays is still controversial.

As AChEls can increase the levels of acetylcholine, a key neurotransmitter involved in memory, they are now utilized as long-term symptomatic treatments for $A D$ patients [101]. $A D$ damages or destroys neurons which produce and use acetylcholine (ACh), then reducing the amount available to carry messages. An AChEl slows the breakdown of ACh by blocking the activity of AChE. By maintaining ACh levels, the drug may help compensate for the loss of functioning neurons. It has also been shown that AChEls intervene with APP cleavage and decrease $A \beta$-induced toxicity through some mechanisms, including interference of the $A \beta$ production, alteration of the A $\beta$ levels, and formation of the soluble form of APP [101]. AChEls can also modulate the expression of $A C h E$ isoforms; increase the expression of nicotinic receptors, via which nicotine can show its protective effect by suppress $A \beta$ toxicity and $A \beta[102]$.

Although modest, AChEls still exhibit a significant effect on the cognitive functions of AD patients, and also show a positive effect on behavior and mood [103]. In general, AChEls are well tolerated, but the possibility of adverse effects still exists. Different AChEls may have different safety profiles [104]. It is believed that the benefits of the usage of AChEls outweigh their risks and costs. AChEls now are considered as primary therapy for the patients with mild to moderate $A D[12]$.

Four different AChEls drugs have been approved by U.S. FDA to treat AD symptoms, which are 
Donepezil, Rivastigmine, Galantamine and Tacrine. Donepezil is approved to treat all stages of $A D$ [101,105,106]; Rivastigmine and Galantamine are approved to treat mild to moderate stages [101]. Although Tacrine is the first AChEl which was approved by the FDA in 1993, some side effects including hepatotoxic effects [107] lead to its rare usage.

The fifth Alzheimer's drug, Memantine, is an NMDA receptor antagonist, which has the capability of suppressing $A \beta$ toxicity and microglia-associated inflammation; preventing hyperphosphorylation of tau; increasing the release of neurotrophic factors from astroglia [108-110].

Memantine works via decreasing glutamate excitotoxicity. Glutamate itself is a vital neurotransmitter which involved in learning and memory in the brain [111]. NMDA receptors permit calcium to enter the cell when combining with glutamate, which is imperative for cell signaling, and then for learning and memory [112]. However, excess glutamate can be released from impaired neurons in $A D$, resulting in chronic overexposure to calcium, which can in turn accelerate neuron impairment [113]. Memantine can partially block the NMDA receptors, and then prevent this destructive chain of events $[108,109]$.

\section{Physical Methods to Treat AD}

\subsection{Clinical Studies of Deep Brain Stimulation}

Although DBS has been approved to treat some progressive neurodegenerative illness, such as Parkinson disease (PD), the quantity of researches concentrating on the potential therapeutic effect of clinical DBS on the dementia has been still quite limited till now. In brief, the DBS technique involves stereotactically guided implantation of one or more electrodes into targeted brain region, and the electric pulses which are generated by a pacemaker implanted in infraclavicular area will be sent through wires and then electrode into brain to influence neural activities [114,115] (see Figure 2).

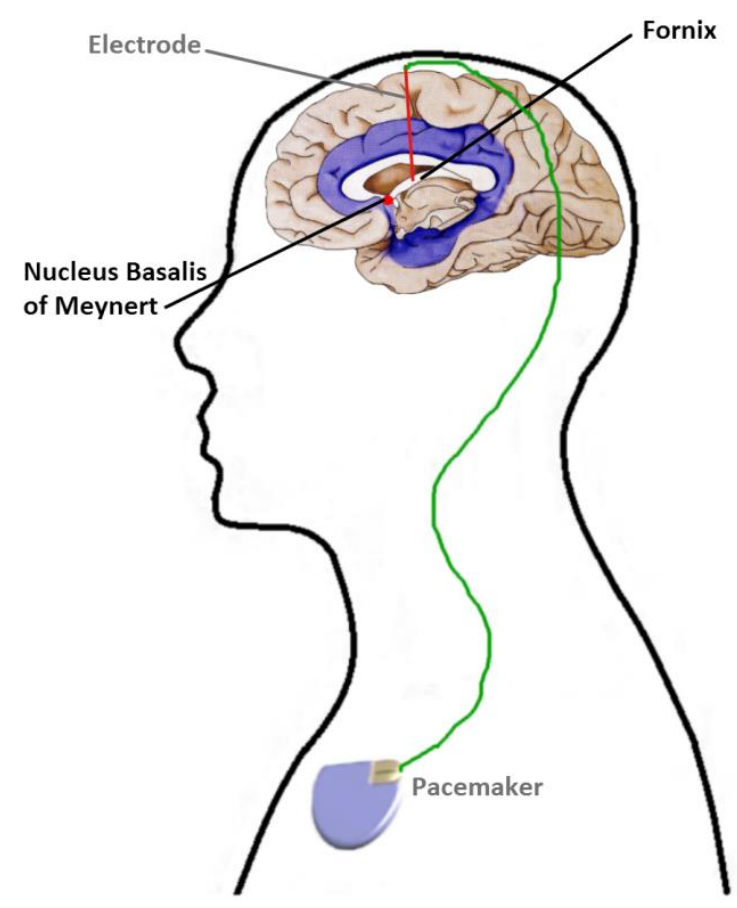

Figure 2.Diagrammatic sketch of deep brain stimulation. DBS is a fairly minimally invasive neurological procedure which involves the implantation of a brain pacemaker sending mild electrical impulses to targeted encephalic regions to treat certain affective and movement disorders

The first clinical DBS treatment that approved by the Food and Drug Administration in 1997 was for 
essential tremor, later for Parkinson's disease in 2002, then for dystonia in 2003, and obsessive-compulsive disorder (OCD) in 2009 [116]. DBS can also be used in research studies of major depression [117,118] and other affective disorders [119], as well as in treatment of chronic pain [120,121], though none of these newer indications have been approved by FDA till now, which may probably due to high complication rates and side effects.

So far, only two feasibility studies focusing on fornix DBS $[122,123]$ with published consequences and one case study [124] and one Phase 1 trial [125] of nucleus basalis of Meynert (NBM) DBS have been undertaken to evaluate if this method could improve the cognitive functions in PD or AD patients.

\subsubsection{Fornix Stimulation}

Fornix, a C-shaped bundle of fibers (axons) in brain, is a key element of the memory circuitry. It carries signals from the hippocampus to the anterior thalamic nuclei $[126,127]$. The main characters of $A D$ are the damages of neurons and neural circuits which relate to cognitive functions. Fornix DBS could have the potential to modulate the neurophysiological activities, which may offer good clinical outcomes. In one study, this treatment was applied to a patient with morbid obesity. It has been shown that hypothalamic/fornix DBS modulated limbic activity of that patient and improved his memory [128]. Then a Phase 1 trial with 6 mild AD patients was investigated by Laxton and his colleagues [122]. Electrodes were located $2 \mathrm{~mm}$ anterior and parallel to the vertical portion of the fornix bilaterally. The neural activities in entorhinal cortex and hippocampus, which was part of the memory circuit, were enhanced by fornix DBS. The damaged glucose utilization in the temporal lobe and parietal lobe was sustained and reversed strikingly after the clinical DBS. Moreover, the improvements of cognitive functions and/or the reduction in the rate of cognitive decline in some patients were clearly demonstrated. Minor side effects in some patients were observed, encompassing minor heat production, sweating, increases in blood pressure and heart rate.

A feasibility study with nine patients was conducted by Fontaine and his colleagues to explore the effect and safety of DBS in AD patients who got mild cognitive deficit [123]. However, only one patient agreed to accept the surgery, and accomplished the study. The patient received stimulation bilaterally for 12 months, and the electrode target was the same as Laxton's study. The memory scores were stabilized comparing to control conditions, and a subjective view of memory improvement was delivered by the only patient herself, without significant 225ehavioural improvement or mood enhancement, however. Furthermore, the glucose metabolism in medial temporal lobes slightly increased. Unfortunately these results are not enough to demonstrate the feasibility of the technique due to the great limitation of the extremely small numbers of the patients.

Another combination of Phase 1 and 2 trial of fornix DBS is now ongoing with about 50 mild probable AD patients to evaluate the acute and long-term safety of this system [129].

\subsubsection{Nucleus Basalis of Meynert (NBM) Stimulation}

It has been shown that NBM lesions can result in neurodegenerative changes in hippocampal mossy fibers and dentate gyrus $[130,131]$, as well as the NADPH-diaphorase enhancement in the dorsal CA1-CA3 of the hippocampus [132]. Characterized by the intrinsic organization, anatomy, and cholinergic innervation, NBM is thought to be an auspicious target structure for clinical DBS in dementia. There is plentiful experimental evidence showing that the NBM projects cholinergic innervation to the whole cortex [133-136], complemented by GABAergic projections and glutaminergic projections from basal forebrain $[124,137]$. 
In the case study of Freund and his colleagues, NBM DBS was applied to a patient who got severe Parkinson-dementia syndrome (PDD) to investigate the potential of this new DBS strategy in modifying the cognitive functions [124]. The only patient who received this surgery is a 71-year-old man with PDD. The target areas were bilateral NBM and subthalamic nucleus (STN). The STN DBS led to the only improvement of motor symptoms, while the NBM DBS resulted in significant improvement cognitive functions, including the attention, alertness, concentration, spontaneity, and drive. Therefore the patient's executive and social functions had been markedly improved. The enhancements in 226ehavioural and cognitive performance might be connected with the effects of irritating residual cholinergic projections and neuronal bodies in NBM.

A clinical study with six mild-to-moderate $A D$ patients was conducted by Kuhn and his colleagues through applying bilateral low-frequency NBM DBS [125]. The whole trial encompassed a 4-week randomized sham-controlled stimulation period and a subsequent 11-month continued open stimulation phase. The consequences were assessed by cognitive subscale of the AD Assessment Scale and other psychological tests. Electroencephalogram (EEG) and positron emission tomography (PET) were also applied to access the changes before and psychological test after the surgery. Nearly no adverse effect showed the expected inner restlessness that one patient declared. Although the patients' average quality of life didn't change, it could also be considered as a safe procedure obviously without significant stimulation-induced adverse effects, since we have to take all limitations of a pilot study into consideration.

\subsection{Animal Researches Related with Deep Brain Stimulation}

There are several relevant animal studies concentrating on DBS-induced changes on behavior, memory, cognition, and/or neurogenesis. 10 brain regions have been explored in different animal models to investigate their functions in memory enhancement, which are fornix, NBM, hippocampus enthorinal cortex (EC), midline thalamic nuclei (MTN), anterior thalamic nucleus (AN), perforant path of hippocampus, dorsal striatum (DS), anterior caudate nucleus, central thalamus (CT), and lateral hypothalamus (LH).

\subsubsection{Fornix and Nucleus Basalis of Meynert (NBM)}

Fornix DBS could antagonize the memory impairing effects resulting from scopolamine injection in rats [138]. The important favorable role of NBM DBS on memory acquisition was investigated in rats [139], in which investigators considered DBS could increase ACh release from NBM neurons that in return helpfully influenced neural plasticity mechanisms. One study suggested that pertaining NBM electrical stimulation facilitates the memory acquisition [140], which supported the fact that NBM could play a part in the early stages of memory formation. Another study also manifested the positive consequences of NBM DBS which were assistance of maintain neuronal plasticity and protective effect on the cortex [141].

\subsubsection{Hippocampus Enthorinal Cortex (EC)}

Application of acute high-frequency DBS in hippocampus EC of mice could lead to a transiently promoted proliferation in the dentate gyrus (DG) [142], and these DBS-induced neurons merged with hippocampal circuits once they were mature.

\subsubsection{Midline Thalamic Nuclei (MTN)}

MTN DBS was found to increase short-term memory in the CA1 of hippocampus in transgenic mice [143] with the results of enhancing object recognition memory during behavioral studies and promoting synaptic plasticity in CA1 of hippocampal slices.

\subsubsection{Anterior Nucleus (AN) of the Thalamus}


The role of AN DBS in memory might depend on current intensity [144]. High current treatment improved hippocampal activity, while relatively high current disrupted memory acquisition. Interestingly, the results of the other study of the same research group showed that the positive role of AN DBS on memory and neurogenesis seemed to be dependent on long-term plastic changes, leading to memory enhancement when the training was conducted at longer intervals [144]. Another study also demonstrated that AN DBS in rats had the ability to improve the hippocampal neurogenesis and reverse experimentally inhibited neurogenesis [145].

\subsubsection{Perforant Path of Hippocampus}

The perforant path is the connection which originates from the hippocampus $E C$, and projects into all areas of the hippocampus. It triggers $\theta$-phase resetting and the release of $\mathrm{ACh}$, the necessary condition of long-term potentiation (LTP) [14]. One study investigated whether perforant path DBS intervened with the circuits related to encoding and retrieving the information of the received stimuli in the working memory task [146]. The result could be explained through this way: $\theta$-phase resetting might synchronize stimuli with the neural circuits in hippocampus to ensure the favorable conditions to facilitate the encoding of the received information into memory.

\subsubsection{Other Brain Regions}

There are other four brain regions related to dementia where DBS could play a role, which are dorsal stritum, anterior caudate nucleus, central thalamus and lateral hypothalamus. Dorsal stritum has been shown to relate to procedural memory [147]. Anterior caudate nucleus is in charge of implementing selective adjustments to the 'associative weights' between sensory cues and motor responses during the learning period [148]. DBS in central thalamus could lead to a complicated situation in arousal, behavior, and cognition [149-151]. With regard to the lateral hypothalamus, the post-training ICSS (the intracranial self-stimulation) could enhance the hippocampus-dependent memories via improving molecular and cellular mechanisms associated with synaptic plasticity, neurogenesis, and neuroprotection [152-155].

\section{Conclusions}

Researches on AD therapy have had some success in the field of symptomatic treatments, but there have also been many failures in the development of disease-modifying drugs. In spite of the frustrating research progress, more and more researchers and clinicians are dedicating all their energy to fighting with this complicated disease, and still more and more clinical and experimental studies are now underway. It would be beneficial to explore different approaches to narrow the gap between successful preclinical investigations and unsuccessful clinical studies via the rationalization of the disease progression mechanisms.

Chemical approaches we have discussed here are divided into two categories, one is disease-modifying therapeutic approaches, and the other is symptomatic treatments, in which the former is focused on the $A \beta$ cascade and hyperphosphorylated tau protein, and the latter is concentrated on cholinesterase and AMDA receptor. Many clinical studies of disease-modifying drugs failed, and still many are now being kept ongoing, but the symptomatic therapies have received some successes. It is difficult for us to estimate the when the successful treatment of $A D$ will be available, but it is easy for us to tell that the consequences from clinical researches are not in accordance with optimistic preclinical studies. The pessimistic outcomes of most clinical studies may be partly due to diverse errors, which can be categorized into the choice of patients, the choice of drugs, the outcome measurements, trial protocols, and optimization of resources [13]. Clearly, the problem is largely due to our limited knowledge to the pathogenesis of AD. As AD is a 
complex multifactorial disorder [156], the details of its pathogenesis are not yet fully understood to support the development of viable drug targets and therapeutic agents. How to solve this problem? On one hand, we need to do further research to explore the real pathogenesis of $A D$, not only limited to $A \beta$ cascade and hyperphosphorylated tau; on the other hand, the strategies of one drug directing at one disease hypothesis to develop $A D$ therapies need to be revised, for a single pathogenic pathway for $A D$ is not possible to be identified [13].

Physical approach using DBS seems to be a feasible and safe treatment for patients with dementia, in consideration of the general low complication rate in about 100,000 PD patients treated with DBS all over the world [157,158]. Currently, the fornix is the most frequently chosen targeting area for treating dementia, including AD and PDD, according to the extremely small number of cases. The potential of the NBM for DBS treatment in dementia is auspicious, which may be due to its characteristics in the anatomy, connectivity of the cholinergic nucleus, and intrinsic organization. Other brain structures we have already mentioned are still lack of human data. The situation in human brain is much more complicated and intricate. The recruitment of patients in clinical evaluation in DBS study on AD was not easy. Clearly there is an important role in the preclinical animal research of DBS for AD, which is extremely limited at present, though. With this data, it may be possible to move toward the rationalization of the mechanisms leading to the disease progression. It must be emphasized that continuing preclinical animal experiments and clinical studies are utmost important to demonstrate the promising efficacy of DBS in future treatment of AD. Apparently, DBS is being used in the general population now. Yet, the strategies to find satisfactory pharmacotherapeutics breakthrough are quite limited. Therefore, DBS may be a good option for some AD patients if it is proved to be a valid treatment. As more clinical data emerge, it will be possible to properly evaluate the applications of DBS in the treatment of $A D$ and other dementia.

\section{Acknowledgement}

We thank the financial support from the Science and Technology Development Fund, Macao S.A.R (FDCT) (project reference no.: 118/2013/A3).

\section{References}

[1] Y. Hong-Qi, S. Zhi-Kun, C. Sheng-Di, Translational Neurodegeneration 1 (2012) 21.

[2] J. Hardy, Neuron 52 (2006) 3-13.

[3] Z. S. Khachaturian, Archives of Neurology 42 (1985) 1097-1105.

[4] K. A. Welsh, N. Butters, J. P. Hughes, R. C. Mohs, A. Heyman, Archives of Neurology 49 (1992) 448452.

[5] S. Artero, M. C. Tierney, J. Touchon, K. Ritchie, Acta Psychiatrica Scandinavica 107 (2003) 390-393.

[6] R. J. Perry, J. R. Hodges, Brain 122 (1999) 383-404.

[7] M. A. L. Ralph, K. Patterson, N. Graham, K. Dawson, J. R. Hodges, Brain 126 (2003) 2350-2362.

[8] D. J. Selkoe, Journal of Alzheimer's Disesae 3 (2001) 75-80.

[9] P. H. Reddy, Brain Research 1415 (2011) 136-148.

[10] B. P. Tseng, K. N. Green, J. L. Chan, M. Blurton-Jones, F. M. LaFerla, Neurobiology of Aging 29 (2008) 1607-1618.

[11] T. E. Golde, Journal of Neurochemistry 99 (2006) 689-707.

[12] D. Galimberti, E. Scarpini, Therapeutic Advances in Neurological Disorders 4 (2011) 203-216.

[13] F. Mangialasche, A. Solomon, B. Winblad, P. Mecocci, M. Kivipelto, Lancet Neurology 9 (2010) 702716.

[14] K. Hardenacke et al., Frontiers in Psychiatry 4 (2013) 159. 
[15] M. L. Kringelbach, N. Jenkinson, S. L. Owen, T. Z. Aziz, Nature Reviews Neuroscience 8 (2007) 623-635.

[16] J. M. Schwalb, C. Hamani, Neurotherapeutics 5 (2008) 3-13.

[17] W. Sue, T. Griffin, American Journal of Clinical Nutrition 83 (2006) 470s-474s.

[18] R. Vassar, Journal of Molecular Neuroscience 23 (2004) 105-114.

[19] T. E. Golde, Brain Pathology 15 (2005) 84-87.

[20] C. Venugopal, C. M. Demos, K. S. Rao, M. A. Pappolla, K. Sambamurti, CNS \& Neurological Disorders Drug Targets 7 (2008) 278-294.

[21] G. Landreth, Q. G. Jiang, S. Mandrekar, M. Heneka, Neurotherapeutics 5 (2008) 481-489.

[22] M. Gold, C. Alderton, M. Zvartau-Hind, S. Egginton, A.M. Saunders, M. Irizarry, S. Craft, G. Landreth, U. Linnamägi, S. Sawchak, Dementia and Geriatric Cognitive Disorders 30 (2010) 131-146.

[23] T. Sato, H. Hanyu, K. Hirao, H. Kanetaka, H. Sakurai, T. Iwamoto, Neurobiology of Aging 32 (2011) 1626-1633.

[24] D. S. Geldmacher, T. Fritsch, M. J. McClendon, G. Landreth, Archives of Neurology 68 (2011) 45-50.

[25] Biomarker Qualification for Risk of Mild Cognitive Impairment (MCl) Due to Alzheimer's Disease (AD) and Safety and Efficacy Evaluation of Pioglitazone in Delaying Its Onset, https://www.clinicaltrials.gov/ct2/show/NCT01931566?term=pioglitazone\%2C+alzheimer\&rank=1 (October 2014).

[26] J. Hey, G. Koelsch, G. Bilcer, A. Jacobs, M. Tolar, J. Tang, International Conference on Alzheimer's Disease (ICAD), Chicago, IL, USA (2008) 26-31.

[27] I. Hussain, J. Hawkins, D. Harrison, C. Hille, G. Wayne, L. Cutler, T. Buck, D. Walter, E. Demont, C. Howes, A. Naylor, P. Jeffrey, M.I. Gonzalez, C. Dingwall, A. Michel, S. Redshaw, J.B. Davis, Journal of Neurochemistry 100 (2007) 802-809.

[28] J. Li, J. Hu, B. Shao, W. Zhou, Y. Cui, C. Dong, J.M. Ezoulin, X. Zhu, W. Ding, F. Heymans, H. Chen, Cellular and Molecular Neurobiology 29 (2009) 589-595.

[29] A. K. Ghosh, M. Brindisi, J. Tang, Journal of Neurochemistry 120 Suppl 1 (2012) 71-83.

[30] G.T. Wong, D. Manfra, F.M. Poulet, Q. Zhang, H. Josien, T. Bara, L. Engstrom, M. Pinzon-Ortiz, J.S. Fine, H.J.J. Lee, L. Zhang, G.A. Higgins, E.M. Parker, Journal of Biological Chemistry 279 (2004) 1287612882.

[31] R.S. Doody, R. Raman, M. Farlow, T. Iwatsubo, B. Vellas, S. Joffe, K. Kieburtz, F. He, X. Sun, R.G. Thomas, P.S. Aisen; Alzheimer's Disease Cooperative Study Steering Committee, E. Siemers, G. Sethuraman, R. Mohs; Semagacestat Study Group, New England Journal of Medicine 369 (2013) 341350.

[32] R. N. Soares H, Sikpi M, et al., Alzheimer's \& Dementia 5 (2009) 252.

[33] V. Ćorić, C.H. van Dyck, S. Salloway, N. Andreasen, M. Brody, R.W. Richter, H. Soininen, S. Thein, T. Shiovitz, G. Pilcher, S. Colby, L. Rollin, R. Dockens, C. Pachai, E. Portelius, U. Andreasson, K. Blennow, H. Soares, C. Albright, H.H. Feldman, R.M. Berman, Archive of Neurology 69 (2012) 1430-1440.

[34] R.L. Martone, H., Zhou, K. Atchison, T. Comery, J.Z. Xu, X. Huang, X. Gong, M. Jin, A. Kreft, B. Harrison, S.C. Mayer, S. Aschmies, C. Gonzales, M.M. Zaleska, D.R. Riddell, E. Wagner, P. Lu, S.C. Sun, J. Sonnenberg-Reines, A. Oganesian, K. Adkins, M.W. Leach, D.W. Clarke, D. Huryn, M. Abou-Gharbia, R. Magolda, J. Bard, G. Frick, S. Raje, S.B. Forlow, C. Balliet, M.E. Burczynski, P.H. Reinhart, H.I. Wan, M.N. Pangalos, J.S. Jacobsen, Journal of Pharmacology and Experimental Therapeutics 331 (2009) 598-608.

[35] M. G. Grossman H, Luo X, LeRoith D, Sano M, Pasinetti G, Alzheimer's \& Dementia 5 (2009) 259.

[36] A Single Site, Randomized, Double-blind, Placebo Controlled Trial of NIC5-15 in Subjects With Alzheimer's Disease, https://clinicaltrials.gov/ct2/show/record/NCT01928420?term=NIC5-15\&rank=1 (August 2013).

[37] T. Tomita, Expert Review of Neurotherapeutics 9 (2009) 661-679.

[38] R.C. Green, L.S. Schneider, D.A. Amato, A.P. Beelen, G. Wilcock, E.A. Swabb, K.H. Zavitz, Journal of the American Medical Association 302 (2009) 2557-2564. 
[39] J. Ross, S. Sharma, J. Winston, M. Nunez, G. Bottini, M. Franceschi, E. Scarpini, E. Frigerio, F. Fiorentini, M. Fernandez, S. Sivilia, L. Giardino, L. Calza, D. Norris, H. Cicirello, D. Casula, B.P. Imbimbo, Current Alzheimer Research 10 (2013) 742-753.

[40] Evaluation of Effects of Multiple Dose Regimens of CHF 5074 on Potential Biomarkers of Neurodegeneration in Subjects With Mild Cognitive Impairment (СT05), https://clinicaltrials.gov/ct2/show/NCT01723670?term=CHF-5074\&rank=7 (February 2015).

[41] B. Vellas, O. Sol, P.J. Snyder, P.J. Ousset, R. Haddad, M. Maurin, J.C. Lemarié, L. Désiré, M.P. Pando, Current Alzheimer Research 8 (2011) 203-212.

[42] R. Etcheberrigaray, M. Tan, I. Dewachter, C. Kuipéri, I. Van der Auwera, S. Wera, L. Qiao, B. Bank, T.J. Nelson, A.P. Kozikowski, F. Van Leuven, D.L. Alkon, Proceedings of the National Academy of Sciences of the United States of America 101 (2004) 11141-11146.

[43] Safety, Efficacy, Pharmacokinetics, and Pharmacodynamics Study of Bryostatin 1 in Patients With Alzheimer's Disease, $\quad$ https://clinicaltrials.gov/ct2/show/NCT00606164?term=Bryostatin1+Alzheimer\&rank=1 (January 2008).

[44] Study to Evaluate the Preliminary Safety, Efficacy, PK and PD of Bryostatin 1 in Patients With Alzheimer's Disease, https://clinicaltrials.gov/ct2/show/NCT02221947?term=Bryostatin1+Alzheimer\&rank=2 (April 2015).

[45] A Study Assessing Bryostatin in the Treatment of Moderately Severe to Severe Alzheimer's Disease, https://clinicaltrials.gov/ct2/show/NCT02431468?term=Bryostatin-1+Alzheimer\&rank=3 (April 2015).

[46] A.D. Snow, J. Cummings, T. Lake, Q. Hu, L. Esposito, J. Cam, M. Hudson, E. Smith, S. Runnels, Alzheimer's \& Dementia 5 (2009) 418.

[47] S. Gilman, M. Koller, R.S. Black, L. Jenkins, S.G. Griffith, N.C. Fox, L. Eisner, L. Kirby, M.B. Rovira, F. Forette, J.M. Orgogozo, AN1792(QS-21)-201 Study Team, Neurology 64 (2005) 1553-1562.

[48] B. Winblad, N. Andreasen, L. Minthon, A. Floesser, G. Imbert, T. Dumortier, R.P. Maguire, K. Blennow, J. Lundmark, M. Staufenbiel, J.M. Orgogozo, A. Graf, Lancet Neurology 11 (2012) 597-604

[49] D. L. Brody, D. M. Holtzman, Annual Review in Neuroscience 31 (2008) 175-193.

[50] Pfizer Pipeline, http://www.pfizer.com/sites/default/files/product-pipeline/pipeline 080913 0.pdf (August 9, 2013).

[51] A. Muhs, D.T. Hickman, M. Pihlgren, N. Chuard, V. Giriens, C. Meerschman, I. van der Auwera, F. van Leuven, M. Sugawara, M.C. Weingertner, B. Bechinger, R. Greferath, N. Kolonko, L. Nagel-Steger, D. Riesner, R.O. Brady, A. Pfeifer, C. Nicolau, Proceedings of the National Academy of Sciences of the United States of America 104 (2007) 9810-9815.

[52] C. Y. W. S. Lynn*, C. L. Finstad, S.-N. Hsu, Y. Kao, C.-F. Wu, P.-N. Wang, M.-J. Chiu, 28th International Conference of Alzheimer's Disease International (2013) 40.

[53] Study to Evaluate Safety, Tolerability and Immunogenicity of Vaccine (UB 311) in Subjects With Alzheimer's Disease, https://clinicaltrials.gov/ct2/show/NCT00965588?term=UB311\&rank=1 (August 2011).

[54] B. Winblad, A. Graf, M. E. Riviere, N. Andreasen, J. M. Ryan, Alzheimer's Research \& Therapy 6 (2014) 7.

[55] D. M. Wilcock, P. T. Jantzen, Q. Li, D. Morgan, M. N. Gordon, Neuroscience 144 (2007) 950-960.

[56] S. Salloway, R. Sperling, S. Gilman, N.C. Fox, K. Blennow, M. Raskind, M. Sabbagh, L.S. Honig, R. Doody, C.H. van Dyck, R. Mulnard, J. Barakos, K.M. Gregg, E. Liu, I. Lieberburg, D. Schenk, R. Black, M. Grundman; Bapineuzumab 201 Clinical Trial Investigators, Neurology 73 (2009) 2061-2070.

[57] S. Salloway, R. Sperling, N.C. Fox, K. Blennow, W. Klunk, M. Raskind, M. Sabbagh, L.S. Honig, A.P. Porsteinsson, S. Ferris, M. Reichert, N. Ketter, B. Nejadnik, V. Guenzler, M. Miloslavsky, D. Wang, Y. Lu, J. Lull, I.C. Tudor, E. Liu, M. Grundman, E. Yuen, R. Black, H.R. Brashear; Bapineuzumab 301 and 302 Clinical Trial Investigators, New England Journal of Medicine 370 (2014) 322-333.

[58] E.R. Siemers, S. Friedrich, R.A. Dean, C.R. Gonzales, M.R. Farlow, S.M. Paul, R.B. Demattos, Clinical Neuropharmacology 33 (2010) 67-73. 
[59] M. Farlow, S.E. Arnold, C.H. van Dyck, P.S. Aisen, B.J. Snider, A.P. Porsteinsson, S. Friedrich, R.A. Dean, C. Gonzales, G. Sethuraman, R.B. DeMattos, R. Mohs, S.M. Paul, E.R. Siemers, Alzheimer's \& Dementia 8 (2012) 261-271.

[60] R.S. Doody, R.G. Thomas, M. Farlow, T. Iwatsubo, B. Vellas, S. Joffe, K. Kieburtz, R. Raman, X. Sun, P.S. Aisen, E. Siemers, H. Liu-Seifert, R. Mohs; Alzheimer's Disease Cooperative Study Steering Committee; Solanezumab Study Group., New England Journal of Medicine 370 (2014) 311-321.

[61] B. Bohrmann, K. Baumann, J. Benz, F. Gerber, W. Huber, F. Knoflach, J. Messer, K. Oroszlan, R. Rauchenberger, W.F. Richter, C. Rothe, M. Urban, M. Bardroff, M. Winter, C. Nordstedt, H. Loetscher, Journal of Alzheimer's Disease 28 (2012) 49-69.

[62] A Study of Gantenerumab in Patients With Mild Alzheimer Disease, https://clinicaltrials.gov/ct2/show/study/NCT02051608?term=gantenerumab+phase+3\&rank=1, (June 2015).

[63] J.W. Landen, Q. Zhao, S. Cohen, M. Borrie, M. Woodward, C.B. Billing Jr, K. Bales, C. Alvey, F. McCush, J. Yang, J.W. Kupiec, M.M. Bednar, Clinical Neuropharmacology 36 (2013) 14-23.

[64] Ponezumab, http://www.alzforum.org/therapeutics/ponezumab (2015).

[65] T. Leyhe, N. Andreasen, M. Simeoni, A. Reich, C.A. von Arnim, X. Tong, A. Yeo, S. Khan, A. Loercher, M. Chalker, C. Hottenstein, H. Zetterberg, J. Hilpert, P. Mistry, Alzheimer's Research and Therapy 6 (2014) 19.

[66] N. Andreasen, M. Simeoni, H. Ostlund, P.I. Lisjo, T. Fladby, A.E. Loercher, G.J. Byrne, F. Murray, P.T. Scott-Stevens, A. Wallin, Y.Y. Zhang, L.H. Bronge, H. Zetterberg, A.K. Nordberg, A.J. Yeo, S.A. Khan, J. Hilpert, P.C. Mistry, PLoS One 10 (2015) e0098153.

[67] R. Dodel, F. Neff, C. Noelker, R. Pul, Y. Du, M. Bacher, W. Oertel, Drugs 70 (2010) 513-528.

[68] K.G. Mawuenyega, W. Sigurdson, V. Ovod, L. Munsell, T. Kasten, J.C. Morris, K.E. Yarasheski, R.J. Bateman, Science 330 (2010) 1774.

[69] S. D. Mulder, R. Veerhuis, M. A. Blankenstein, H. M. Nielsen, Experimental Neurology 233 (2012) 373379.

[70] C. Bauer, R. Pardossi-Piquard, J. Dunys, M. Roy, F. Checler, Journal of Alzheimer's Disease 27 (2011) 511-520.

[71] N.N. Nalivaeva, N.D. Belyaev, D.I. Lewis, A.R. Pickles, N.Z. Makova, D.I. Bagrova, N.M. Dubrovskaya, S.A. Plesneva, I.A. Zhuravin, A.J. Turner, Journal of Molecular Neuroscience 46 (2012) 569-577.

[72] H. Amijee, D. I. C. Scopes, Journal of Alzheimers Disease 17 (2009) 33-47.

[73] P.A. Adlard, R.A. Cherny, D.I. Finkelstein, E. Gautier, E. Robb, M. Cortes, I. Volitakis, X. Liu, J.P. Smith, K. Perez, K. Laughton, Q.X. Li, S.A. Charman, J.A. Nicolazzo, S. Wilkins, K. Deleva, T. Lynch, G. Kok, C.W. Ritchie, R.E. Tanzi, R. Cappai, C.L. Masters, K.J. Barnham, A.I. Bush, Neuron 59 (2008) 43-55.

[74] There is no evidence that MPACs (PBT1 or PBT2) are of benefit in Alzheimer's dementia, http://www.cochrane.org/CD005380/DEMENTIA there-is-no-evidence-that-mpacs-pbt1-or-pbt2-areof-benefit-in-alzheimers-dementia (February 21, 2014).

[75] PBT2 Takes a Dive in Phase 2 Alzheimer's Trial, http://www.alzforum.org/news/research-news/pbt2takes-dive-phase-2-alzheimers-trial (Apr 01, 2014).

[76] S. Salloway, R. Sperling, R. Keren, A.P. Porsteinsson, C.H. van Dyck, P.N. Tariot, S. Gilman, D. Arnold, S. Abushakra, C. Hernandez, G. Crans, E. Liang, G. Quinn, M. Bairu, A. Pastrak, J.M. Cedarbaum; ELND005-AD201 Investigators, Neurology 77 (2011) 1253-1262.

[77] R. O. Sanchez-Mejia, J.W. Newman, S. Toh, G.Q. Yu, Y. Zhou, B. Halabisky, M. Cissé, K. Scearce-Levie, I.H. Cheng, L. Gan, J.J. Palop, J.V. Bonventre, L. Mucke, Nature Neuroscience 11 (2008) 1311-1318.

[78] E.D. Roberson, K. Scearce-Levie, J.J. Palop, F. Yan, I.H. Cheng, T. Wu, H. Gerstein, G.Q. Yu, L. Mucke, Science 316 (2007) 750-754.

[79] T. A. Schoenfeld, R. A. Obar, International Review of Cytology 151 (1994) 67-137.

[80] D. Couchie, C. Mavilia, I.S. Georgieff, R.K. Liem, M.L. Shelanski, J. Nunez, Proceedings of the National Academy of Sciences of the United States of America 89 (1992) 4378-4381. 
[81] A. Mudher, S. Lovestone, Trends in Neuroscience 25 (2002) 22-26.

[82] G. V. Johnson, W. H. Stoothoff, Journal of Cell Science 117 (2004) 5721-5729.

[83] R. Medeiros, D. Baglietto-Vargas, F. M. LaFerla, CNS Neuroscience and Therapeutics 17 (2011) 514524.

[84] J.P. Hu, J.W. Xie, C.Y. Wang, T. Wang, X. Wang, S.L. Wang, W.P. Teng, Z.Y. Wang, Brain Research Bulletin 85 (2011) 194-200.

[85] P. N. Tariot, P. S. Aisen, Journal of Clinical Psychiatry 70 (2009) 919-921.

[86] A. P. Tariot, P. Aisen, J. Cummings, L. Jakimovich, L. Schneider, R. Thomas, L. Becerra, R. Loy, Alzheimer's \& Dementia 5 (2009) 84-85.

[87] A. Martinez, D. I. Perez, Journal of Alzheimers Disease 15 (2008) 181-191.

[88] A. Caccamo, S. Oddo, L. X. Tran, F. M. LaFerla, American Journal of Pathology 170 (2007) 1669-1675.

[89] H. Hampel, M. Ewers, K. Bürger, P. Annas, A. Mörtberg, A. Bogstedt, L. Frölich, J. Schröder, P. Schönknecht, M.W. Riepe, I. Kraft, T. Gasser, T. Leyhe, H.J. Möller, H. Basun, Journal of Clinical Psychiatry 70 (2009) 922-931.

[90] W. Noble, V. Olm, K. Takata, E. Casey, O. Mary, J. Meyerson, K. Gaynor, J. LaFrancois, L. Wang, T. Kondo, P. Davies, M. Burns, A. Veer, R. Nixon, D. Dickson, Y. Matsuoka, M. Ahlijanian, L.F. Lau, K. Duff, Neuron 38 (2003) 555-565.

[91] Y. Choi, H.S. Kim, K.Y. Shin, E.M. Kim, M. Kim, H.S. Kim, C.H. Park, Y.H. Jeong, J. Yoo, J.P. Lee, K.A. Chang, S. Kim, Y.H. Suh, Neuropsychopharmacology 32 (2007) 2393-2404.

[92] M. Pickhardt, Z. Gazova, M. von Bergen, I. Khlistunova, Y. Wang, A. Hascher, E.M. Mandelkow, J. Biernat, E. Mandelkow, Journal of Biological Chemistry 280 (2005) 3628-363.

[93] C. Ballatore, K.R. Brunden, J.Q. Trojanowski, V.M. Lee, A.B. Smith 3rd, D.M. Huryn, Current Topics in Medicinal Chemistry 11 (2011) 317-330.

[94] F. Dou, W.J. Netzer, K. Tanemura, F. Li, F.U. Hartl, A. Takashima, G.K. Gouras, P. Greengard, H. Xu, Proceedings of the National Academy of Sciences of the United States of America 100 (2003) 721-726.

[95] C. A. Dickey, J. Dunmore, B. Lu, J.W. Wang, W.C. Lee, A. Kamal, F. Burrows, C. Eckman, M. Hutton, L. Petrucelli, FASEB Journal 20 (2006) 753-755.

[96] E. M. Sigurdsson, Journal of Alzheimer's Disease 15 (2008) 157-168.

[97] K. R. Brunden, B. Zhang, J. Carroll, Y. Yao, J.S. Potuzak, A.M. Hogan, M. Iba, M.J. James, S.X. Xie, C. Ballatore, A.B. Smith 3rd, V.M. Lee, J.Q. Trojanowski, Journal of Neuroscience 30 (2010) 13861-13866.

[98] B. Zhang, J. Carroll, J.Q. Trojanowski, Y. Yao, M. Iba, J.S. Potuzak, A.M. Hogan, S.X. Xie, C. Ballatore, A.B. Smith 3rd, V.M. Lee, K.R. Brunden, Journal of Neuroscience 32 (2012) 3601-3611.

[99] D. E. Hurtado, L. Molina-Porcel, M. Iba, A.K. Aboagye, S.M. Paul, J.Q. Trojanowski, V. M.Y. Lee, American Journal of Pathology 177 (2010) 1977-1988.

[100] Study to Evaluate the Safety, Tolerability and the Effect of BMS-241027 on Cerebrospinal Fluid Biomarkers in Subjects With Mild Alzheimer's Disease, https://clinicaltrials.gov/ct2/show/NCT01492374?term=BMS-241027\&rank=1 (October 2013).

[101] A. Nordberg, Alzheimer Disease and Associated Disorders 20 (2006) S12-S18.

[102] L. R. Fodero, S.S. Mok, D. Losic, L.L. Martin, M.I. Aguilar, C.J. Barrow, B.G. Livett, D.H. Small, Journal of Neurochemistry 88 (2004) 1186-1193.

[103] J. Birks, Cochrane Database of Systematic Reviews (2006) CD005593.

[104] M. Mehta, A. Adem, M. Sabbagh, International Journal of Alzheimer's Disease 2012 (2012) 728983.

[105] B. Winblad, L. Kilander, S. Eriksson, L. Minthon, S. Båtsman, A.L. Wetterholm, C. Jansson-Blixt, A. Haglund; Severe Alzheimer's Disease Study Group, Lancet 367 (2006) 1057-1065.

[106] B. Winblad, American Journal of Alzheimer's Disease \& Other Dementias 24 (2009) 185-192.

[107] P. B. Watkins, H. J. Zimmerman, M. J. Knapp, S. I. Gracon, K. W. Lewis, Journal of the American Medical Association 271 (1994) 992-998.

[108] G. L. Wenk, C. G. Parsons, W. Danysz, Behavioural Pharmacology 17 (2006) 411-424. 
[109] J. J. Pei, M. Sjogren, B. Winblad, Current Opinion in Psychiatry 21 (2008) 555-561.

[110] H.M. Wu, N.S. Tzeng, L. Qian, S.J. Wei, X. Hu, S.H. Chen, S.M. Rawls, P. Flood, J.S. Hong, R.B. Lu, Neuropsychopharmacology 34 (2009) 2344-2357.

[111] G. Riedel, B. Platt, J. Micheau, Behavioural Brain Research 140 (2003) 1-47.

[112] A. Sanchez-Perez, M. Llansola, O. Cauli, V. Felipo, Cerebellum 4 (2005) 162-170.

[113] U. Wojda, E. Salinska, J. Kuznicki, IUBMB Life 60 (2008) 575-590.

[114] E. Bell, G. Mathieu, E. Racine, Surgical Neurology 72 (2009) 577-586; discussion 586.

[115] P. E. Holtzheimer, H. S. Mayberg, Annual Review of Neuroscience 34 (2011) 289-307.

[116] S. Miocinovic, S. Somayajula, S. Chitnis, J. L. Vitek, Journal of the American Medical Association Neurology 70 (2013) 163-171.

[117] R.J. Anderson, M.A. Frye, O.A. Abulseoud, K.H. Lee, J.A. McGillivray, M Berk, S.J. Tye, Neuroscience and Biobehavioral Reviews 36 (2012) 1920-1933.

[118] T.E. Schlaepfer, M.X. Cohen, C. Frick, M. Kosel, D. Brodesser, N. Axmacher, A.Y. Joe, M. Kreft, D. Lenartz, V. Sturm, Neuropsychopharmacology 33 (2008) 368-377.

[119] B. Velasques, C. Diniz, S. Teixeira, C. Cartier, C. Peressutti, F. Silva, M. de Carvalho, A. Novaes, J. Bittencourt, A.E. Nardi, E. Cheniaux, L. Basile, M. Cagy, R. Piedade, P. Ribeiro, CNS \& Neurological Disorders-Drug Targets 13 (2014) 961-971.

[120] R. F. Young, T. Brechner, Cancer 57 (1986) 1266-1272.

[121] B. Jenkins, S. J. Tepper, Headache 51 (2011) 1408-1418.

[122] A.W. Laxton, D.F. Tang-Wai, M.P. McAndrews, D. Zumsteg, R. Wennberg, R. Keren, J. Wherrett, G. Naglie, C. Hamani, G.S. Smith, A.M. Lozano, Annals of Neurology 68 (2010) 521-534.

[123] D. Fontaine , A. Deudon, J.J. Lemaire, M. Razzouk, P. Viau, J. Darcourt, P. Robert, Journal of Alzheimer's Disease 34 (2013) 315-323.

[124] H.J. Freund, J. Kuhn, D. Lenartz, J.K. Mai, T. Schnell, J. Klosterkoetter, V. Sturm, Archives of Neurology 66 (2009) 781-785.

[125] J. Kuhn, K. Hardenacke, D. Lenartz, T. Gruendler, M. Ullsperger, C. Bartsch, J.K. Mai, K. Zilles, A. Bauer, A. Matusch, R.J. Schulz, M. Noreik, C.P. Bührle, D. Maintz, C. Woopen, P. Häussermann, M. Hellmich, J. Klosterkötter, J. Wiltfang, M. Maarouf, H.J. Freund, V. Sturm, Molecular Psychiatry 20 (2015) 353360.

[126] J. P. Aggleton, R. Desimone, M. Mishkin, Journal of Comparative Neurology 243 (1986) $409-421$.

[127] N. Neave, S. Lloyd, A. Sahgal, J. P. Aggleton, Behavioural Brain Research 65 (1994) 89-101.

[128] C. Hamani, M.P. McAndrews, M. Cohn, M. Oh, D. Zumsteg, C.M. Shapiro, R.A. Wennberg, A.M. Lozano, Annals of Neurology 63 (2008) 119-123.

[129] Advance DBS-f in Patients With Mild Probable Alzheimer's Disease, https://clinicaltrials.gov/ct2/show/NCT01608061?term=fornix+DBS\&rank=4 (March 2015).

[130] F. Amenta, E. Bronzetti, M.G. Caporali, E. Ciriaco, G.P. Germana, T. Niglio, A. Ricci, A.S. de Carolis, Archives of Gerontology and Geriatrics 12 (1991) 49-58.

[131] I. Panocka, S. Sagratella, A. Scotti de Carolis, Y. C. Zeng, F. Amenta, Neuroscience Letter 190 (1995) 207-211.

[132] M. Sabbatini et al., Mechanisms of Ageing and Development 107 (1999) 147-157.

[133] V. Parikh, M. Sarter, Molecular and Biophysical Mechanisms of Arousal, Alertness, and Attention 1129 (2008) 225-235.

[134] B. J. Everitt, T. W. Robbins, Annual Review of Psychology 48 (1997) 649-684.

[135] M. Sarter, J. P. Bruno, Brain Research Reviews 23 (1997) 28-46.

[136] L. Zaborszky, K. Pang, J. Somogyi, Z. Nadasdy, I. Kallo, Advancing from the Ventral Striatum to the Extended Amygdala 877 (1999) 339-367. 
[137] A. Montero-Pastor, A. Vale-Martinez, G. G. Guillazo-Blanch, M. Marti-Nicolovius, Behavioural Brain Research 154 (2004) 41-54.

[138] S. Hescham, L.W. Lim, A. Jahanshahi, H.W. Steinbusch, J. Prickaerts, A Blokland, Y. Temel, Brain Stimulation 6 (2013) 72-77.

[139] A. Montero-Pastor, A. Vale-Martinez, G. Guillazo-Blanch, M. Marti-Nicolovius, Behavioural Brain Research 154 (2004) 41-54.

[140] N. Boix-Trelis, A. Vale-Martinez, G. Guillazo-Blanch, D. Costa-Miserachs, M. Marti-Nicolovius, Learn Memory 13 (2006) 783-793.

[141] H. Hotta, F. Kagitani, M. Kondo, S. Uchida, Neuroscience Research 63 (2009) 122-128.

[142] S.S.D. Stone, C.M. Teixeira, L.M. DeVito, K. Zaslavsky, S.A. Josselyn, A.M. Lozano, P.W. Frankland, Journal of Neuroscience 31 (2011) 13469-13484.

[143] I. Arrieta-Cruz, C. Pavlides, G. M. Pasinetti, Translational Neuroscience 1 (2010) 188-194.

[144] C. Hamani, S. S. Stone, A. Garten, A. M. Lozano, G. Winocur, Experimental Neurology 232 (2011) 100104.

[145] H. Toda, C. Hamani, A. P. Fawcett, W. D. Hutchison, A. M. Lozano, Journal of Neurosurgery 108 (2008) 132-138.

[146] H. McCartney, A. D. Johnson, Z. M. Weil, B. Givens, Hippocampus 14 (2004) 684-687.

[147] A. Schumacher, A. P. de Vasconcelos, L. Lecourtier, A. Moser, J. C. Cassel, Behavioural Brain Research 222 (2011) 368-374.

[148] Z. M. Williams, E. N. Eskandar, Nature Neuroscience 9 (2006) 562-568.

[149] A.C. Smith, S.A. Shah, A.E. Hudson, K.P. Purpura, J.D. Victor, E.N. Brown, N.D. Schiff, Journal of Neuroscience Methods 183 (2009) 267-276.

[150] S. A. Shah, J. L. Baker, J. W. Ryou, K. P. Purpura, N. D. Schiff, Conference Proceeding IEEE Engineering in Medicine and Biology Society. 2009 (2009) 3314-3317.

[151] R. G. Mair, J. R. Hembrook, Journal of Neuroscience 28 (2008) 14293-14300.

[152] C. Soriano-Mas, D. Redolar-Ripoll, L. Aldavert-Vera, I. Morgado-Bernal, P. Segura-Torres, Behavioural Brain Research 160 (2005) 141-147.

[153] C. Soriano-Mas, D. Redolar-Ripoll, G. Guillazo-Blanch, I. Morgado-Bernal, P. Segura-Torres, Brain Research Bulletin 74 (2007) 51-57.

[154] G. Huguet, L. Aldavert-Vera, E. Kádár, S. Peña de Ortiz, I. Morgado-Bernal, P. Segura-Torres, Neuroscience 162 (2009) 359-374.

[155] E. Kadar, L. Aldavert-Vera, G. Huguet, D. Costa-Miserachs, I. Morgado-Bernal, P. Segura-Torres, Genes, Brain and Behavior 10 (2011) 69-77.

[156] H. W. Querfurth, F. M. LaFerla, New England Journal of Medicine 362 (2010) 329-344.

[157] G. Deuschl, C. Schade-Brittinger, P. Krack, J. Volkmann, H. Schäfer, K. Bötzel, C. Daniels, A. Deutschländer, U. Dillmann, W. Eisner, D. Gruber, W. Hamel, J. Herzog, R. Hilker, S. Klebe, M. Kloss, J. Koy, M. Krause, A. Kupsch, D. Lorenz, S. Lorenzl, H.M. Mehdorn, J.R. Moringlane, W. Oertel, M.O. Pinsker, H. Reichmann, A. Reuss, G.H. Schneider, A. Schnitzler, U. Steude, V. Sturm, L. Timmermann, V. Tronnier, T. Trottenberg, L. Wojtecki, E. Wolf, W. Poewe, J. Voges; German Parkinson Study Group, Neurostimulation Section, New England Journal of Medicine 355 (2006) 896-908.

[158] J. Voges, Y. Waerzeggers, M. Maarouf, R. Lehrke, A. Koulousakis, D. Lenartz, V. Sturm, Journal of Neurology, Neurosurgery \& Psychiatry 77 (2006) 868-872.

C2015 by the authors; licensee IAPC, Zagreb, Croatia. This article is an open-access article distributed under the terms and conditions of the Creative Commons Attribution license(http://creativecommons.org/licenses/by/3.0/) (cc)) EY 